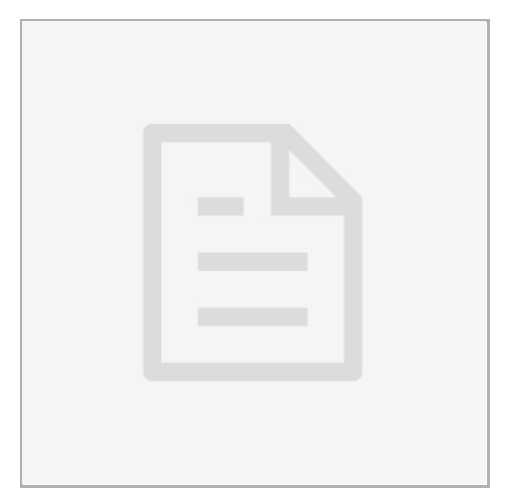

MAR 01, 2021

\section{open $\boldsymbol{O}$ access}

DOI:

dx.doi.org/10.17504/protocol s.io.bi5kkg4w

Document Citation: Sebasti ão Santos 2021.

Rehabilitation protocol after varization osteotomy - Case Study. protocols.io https://dx.doi.org/10.17504/p rotocols. io. bi5kkg4w

License: This is an open access document distributed under the terms of the Creative Commons Attribution License, which permits unrestricted use, distribution, and reproduction in any medium, provided the original author and source are credited

Created: Jul 29, 2020

Last Modified: Mar 01, 2021

DOCUMENT integer ID: 39820

Keywords: Therapeutic Program; aquatic environment; rehabilitation; case study; varization osteotomy

\section{(3) Rehabilitation protocol after varization osteotomy - Case Study}

\author{
Sebastião Santos ${ }^{1,2}$
}

${ }^{1}$ CIDESD (The Research Center in Sports Sciences, Health Sciences and Human Development), Vila Real, Portugal;

${ }^{2}$ Professor, Ministery of Education, Portugal<smiles>C1CCCCCC1</smiles>

\section{Sebastião Santos}

\section{ABSTRACT}

Background: Knee rehabilitation using therapeutic exercises in the aquatic environment has been used in order to initiate lower limb rehabilitation earlier and improve joint movements, as it reduces pain and allows for earlier weight bearing. Objective: To develop and describe the effects of an aquatic therapeutic exercise program in a case study of tibial osteotomy and varus femur. Methods: A 15-yearold girl undergoing a tibial and femoral varus osteotomy completed an aquatic therapeutic exercise program consisting of a total of 30 sessions ( 3 sessions per week of 60 minutes). The subject was evaluated at two different times (at the beginning and end of the intervention). Results: There was an improvement in the various parameters evaluated (knee flexion: $66^{\circ}$ vs $125^{\circ}$; knee extension: $-7^{\circ}$ vs $-1^{\circ}$; pain on movement: $6 / 10$ vs $0 / 10$ ). Conclusion: The aquatic therapeutic exercise program used in this study has beneficial effects in a clinical case of tibial osteotomy and varus femur.

\title{
Rehabilitation protocol after varization osteotomy - Case Study
}


${ }^{1}$ CIDESD (The Research Center in Sports Sciences, Health Sciences and Human Development), Vila Real, Portugal

${ }^{2}$ Professor, Ministery of Education, Portugal

Orcid: https://orcid.org/0000-0003-3647-2168

\begin{abstract}
Background: Knee rehabilitation using therapeutic exercises in the aquatic environment has been used in order to initiate lower limb rehabilitation earlier and improve joint movements, as it reduces pain and allows for earlier weight bearing. Objective: To develop and describe the effects of an aquatic therapeutic exercise program in a case study of tibial osteotomy and varus femur. Methods: A 15-year-old girl undergoing a tibial and femoral varus osteotomy completed an aquatic therapeutic exercise program consisting of a total of 30 sessions (3 sessions per week of 60 minutes). The subject was evaluated at two different times (at the beginning and end of the intervention). Results: There was an improvement in the various parameters evaluated (knee flexion: $66^{\circ}$ vs $125^{\circ}$; knee extension: $-7^{\circ}$ vs $-1^{\circ}$; pain on movement: $6 / 10$ vs $0 / 10$ ). Conclusion: The aquatic therapeutic exercise program used in this study has beneficial effects in a clinical case of tibial osteotomy and varus femur.
\end{abstract}

Keywords: Therapeutic Program; aquatic environment; rehabilitation; case study; varization osteotomy

\title{
Introduction
}

The knee is a hinge joint, comprised between the lower end of the femur (distal epiphysis of the femur) and the upper end of the tibia (proximal tibial epiphysis) $(1,2,3,4,5)$. Internal risk factors, external risk factors, incidents influence the load and its tolerance but also the properties and size of ligaments are influenced by age, sex, body size and formation ${ }^{(6)}$.Tibial and femur osteotomies, usually of valgization and varization respectively, are surgeries performed to correct lower limb axis deviations, commonly described as bent legs (knees in or out, also referred to as genu valgus or varus, respectively). The occurrence of these deformities lead to alteration in the load distribution / "weight" at the knee joint level, internal compartment in the varus knee and external compartment in the valgus knee. This mechanical overload causes cartilage wear, which by definition corresponds to arthrosis associated with ruptured menisci. These tears are the most important and frequent factor in the pain experienced by the patient. The new bone position is maintained by placing fixation material in titanium or steel (usually titanium, allowing nuclear magnetic resonance), which will allow bone consolidation in the desired position. In this postoperative period, lower limb support may be limited or prohibited for reasons inherent to surgery or treatment of associated injuries (menisci or cartilage).

\section{Aquatic exercise program}

Aquatic physical therapy can be safely considered and applied at this early postoperative stage ${ }^{(7)}$. Postoperative rehabilitation is to prepare the patient to return to pre-injury activity levels while minimizing the risk of future injury ${ }^{(8)}$. Water exercises become less painful than in a dry place ${ }^{(9)}$. Aquatic exercises facilitate movement due to decreased gravity. Implementing an aquatic rehabilitation program will be beneficial in the short term, although it may not offer 
an improvement in pain ${ }^{(10)}$.

\section{Case study}

The case study values the work done and the results obtained with the subject without extrapolating them, aiming to value the description of a situation, as well as the explanation of results, the identification of the relations between cause and effect ${ }^{(11)}$, not forgetting the decision making, convenient for the case study, making them very useful for analyzing, describing and illustrating situations in a case record ${ }^{(12)}$.

\section{Objective of the study}

The study was developed with the objective of developing the protocol of an aquatic therapeutic exercise rehabilitation program. The initial draft was developed using expert opinions $(13,14)$, after which it was applied in this case study.

\section{Case}

The female subject at the age of 14 years underwent surgery, a tibial osteotomy and a varus femur (surgical intervention in the right lower limb).

\section{Procedures}

The research was conducted in acoordance with international ethical guidelines and anonymity was preserved. The intervention took place for 10 consecutive weeks, three times a week, for a total of 30 sessions. With the presence of the responsible technician (Rehabilitation in Exercise Medicine and Sport). The aquatic rehabilitation program (Appendix 1) was carried out in a $16.66 \mathrm{~m}$ water tank with a depth ranging from $0.90 \mathrm{~m}$ to $1.50 \mathrm{~m}$ with the water temperature between $28^{\circ} \mathrm{C}$ and $29^{\circ} \mathrm{C}$.

Evaluations were performed before and after the application of the aquatic rehabilitation program. The parameters evaluated at the two moments of evaluation were as follows: Pain through Visual Analog Scale (VAS). This scale consists of a horizontal or vertical line, 10 centimeters long, which has the "No Pain" rating on one end and the "Maximum Pain" rating on the other. intensity of your pain. Thus, there is an equivalence between the intensity of pain and the position indicated on the straight line. The distance between the beginning of the zero line and the marked location is then measured (in centimeters), thus obtaining a numerical classification which will be indicated on the record sheet (Normative Circular 9 / DGCG, 2003).

Articular amplitudes were measured with the universal goniometer, according to the procedures indicated by Norkin and White ${ }^{(15)}$.

\section{Results}

After the initial evaluation, the main problems identified were pain on movement, restriction of knee joint amplitudes, changes in the muscular system, namely, decrease in thigh muscle mass (comparison with the lateral limb), strength deficit in the flexors and extensors of the knee. knee and postural imbalance. Table 1 presents the results obtained in the evaluation of knee joint amplitudes. In the first evaluation performed, there was limitation of the amplitudes of the right knee in relation to the left, especially in flexion where the difference between the two limbs was $63^{\circ}$. The subject had some discrepancies in the left knee, however during the treatment the amplitudes of both knees evolved favorably, having reached full extension and only a $9^{\circ}$ difference in right knee flexion, compared to the left.

Table 1 - Evaluation of joint amplitudes (1st and 2nd evaluation moment) 


\begin{tabular}{|l|l|l|l|l|}
\hline \hline $\begin{array}{l}\text { Evaluation } \\
\text { moment }\end{array}$ & $\begin{array}{l}\text { Knee } \\
\text { Extension }\end{array}$ & $\begin{array}{l}\text { Knee } \\
\text { Flexion }\end{array}$ & \\
\hline & Right Knee & Left Knee & Right Knee & Left Knee \\
\hline $\begin{array}{c}1 \mathrm{st} \\
\text { moment }\end{array}$ & $-7^{\circ}$ & $-1^{\circ}$ & $66^{\circ}$ & $128^{\circ}$ \\
\hline $\begin{array}{c}2 \mathrm{nd} \\
\text { moment }\end{array}$ & $-7^{\circ}$ & $0^{\circ}$ & $125^{\circ}$ & $134^{\circ}$ \\
\hline
\end{tabular}

Looking at table 2, we found that the values of pain on movement from the 1 st moment to the 2 nd were greatly reduced and that it was no longer present at the 2 nd assessment moment.

Table 2 - Assessment of pain on movement (1st and 2nd assessment moment)

\begin{tabular}{|l|l|}
\hline \hline assessment moment & $\begin{array}{l}\text { Pain } \\
\text { with movement }\end{array}$ \\
\hline 1st moment & $6 / 10$ \\
\hline 2nd moment & $0 / 10$ \\
\hline
\end{tabular}

Discussion

The results obtained in this case study with a ten-week rehabilitation program of therapeutic exercises in the aquatic environment point to an improvement in joint amplitudes, strength increase, balance improvement, reduction of pain to movement and improvement The patient sees the clinical situation of his knee as its functionality, leisure and quality of life. These results conflict with other studies that report significant improvements in aquatic ${ }^{(16)}$ work compared to dry work ${ }^{(7,17,18)}$. Contrary to other studies ${ }^{(19)}$ with the applications of a dry program, with the incidence of specific work one on member, in our study (aquatic program) the exercises are performer with both lower limbs (appendix 1), with physiological evolution in both and with reduced pain Distal femoral osteomotia offers the advantages of rapid pain reduction and short rehabilitation in young and active patients subjected to heavy knee loads $(20,21,22)$. In this case study, the rehabilitation of tibial and femoral osteotomy was performed in an aquatic environment, following an exercise program built by the author according to the bibliography and pre-established objectives. The rehabilitation program followed a protocol (appendix 1) in the aquatic environment defined by us, with a favorable clinical evolution, with improvements in all evaluated parameters, namely: mobility, pain, muscle strength, balance and knee functionality, as other studies ${ }^{(23)}$. The mobility acquired by the user went beyond what would be expected with a terrestrial rehabilitation, according to other studies with different protocols but performed in the aquatic environment ${ }^{(14)}$, the flexion range of motion are between $120^{\circ}$ and $130^{\circ}$, and in this case study, the user presented these values. We can see that our results are quite significant, as well as other protocols ${ }^{(24)}$ carried out in the context of water.

There is a belief that exercise can damage cartilage, creating a predominant barrier to the implementation of therapeutic exercises in the knee joint to be treated. The benefits of physical activity and therapeutic exercise extend far beyond improvements in pain, function and quality of life of patients with knee problems (Osteoarthritis) (25). These results may provide a scientific basis for further research on the effectiveness and complementary of an aquatic rehabilitation program after surgical intervention.

\section{Conclusions}


The results showed an improvement in all aspects evaluated, namely pain, mobility, muscle strength, balance and knee functionality. Thus we can consider that the program of therapeutic exercises in aquatic environment had positive effects in this case of rehabilitation study after varicose osteotomy. In summary, this functional analysis can define a new specific perspective for the rehabilitation protocol of certain patients.

\section{Limitations}

The use of a control group would have reinforced the case study in question, bringing new results and probably obtaining conclusions that reinforced this protocol.

\section{Ethical approval and consent to participate}

The legal guardian and the subject were previously informed about the purpose of the intervention and the procedure and agreed and gave informed consent in accordance with the Declaration of Helsinki (Appendix 2). Data confidentiality and anonymity were also ensured.

\section{References}

1.Amis A,Dawkins G. Functional Anatomy of the Anterior Cruciate Ligament - Fibre Bundle related to Ligament Replacement and Injuries, J Bone Joint Surg. 1991;73B(2): 2-8.

2. Schulz D. Anatomia. In Ellenbecker, T., Reabilitação dos Ligamentos do Joelho. Brasil: Editora Manole; 2002.1-15.

3. Paine R, Johnson R. Avaliação por instrumentos. In Ellenbecker, T. Reabilitação dos Ligamentos do Joelho. Brasil: Editora Manole; 2002.43-74.

4. Pina J. Anatomia Humana da Locomoção (Parte I). Lisboa: LIDEL - edições técnicas; 2000

5. Kapandji, I. Fisiologia Articular. 5a Edição, Vol. II: Editora Manole; 1990.120-140.

6. Bahr R, Kraushaug T. Understanding injury mechanisms: a key component of preventing injuries in sport, $\mathrm{Br} \mathrm{J}$ Sports Med. 2005;39:324-329. [doi: 10.1136/bjsm.2005.018341]

7. Rahmann A, Brauer S, Nitz J. A Specific Inpatient Aquatic Physiotherapy Program Improves Strength After Total Hip or Knee Replacement Surgery: A Randomized Controlled Trial, Arch Phys Med Rehabil. 2009;90(5):745-755.

[doi.org/10.1016/j.apmr.2008.12.011]

8. Paterno M, Filipa A. Rehabilitation and Return to Sports After Anterior Cruciate Ligament Reconstruction in the Young Athlete. In Parikh S, The Pediatric Anterior Cruciate Ligament.Champagne: Springer; 2017;183-198.

9. Heywood S, McClelland J, Geigled P, et al. Force during functional exercises on land and in water in older adults with and without knee osteoarthritis: Implications for rehabilitation, Knee. 2019;26(1):61-72. [doi:

10.1016/j.knee.2018.11.003]

10. WangT, Belza B, Thompson T, et al. Effects of aquatic exercise on flexibility, strength and aerobic fitness in adults with osteoarthritis of the hip or knee, J Adv Nurs. 2007;57(2):141-152. [doi: 10.1111/j.1365-2648.2006.04102.x]

11. Serrano G. Investigación cualitativa. retos e interrogantes - I. Métodos. Madrid: Ed. La Muralla; 2004

12. Gomez R, Flores J, Jimènez E. Metodologia de la Investigacion Cualitativa. Malaga: Ediciones Aljibe; 1996

13. Santos S, Sarmento H, Alves J, Campaniço J. Construcción de un instrumento para la observación y el análisis de las interacciones en el waterpolo, Rev Psicol Deporte. 2014;23(1):191-200.

14. Jahan A, Dmitrievna M, Ismayilova M. Development and preliminary validation of a new protocol for postoperative rehabilitation of partial meniscectomy, J H Sport Exerc. 2018;13(3):577-600. [doi.org/10.14198/jhse.2018.133.0916]

15. Norkin C, White J. Medida do Movimento Articular: Manual de Goniometria. Brasil: Artes Médicas; 1997

16. Lovecchio N, Sciumè L, Zago M, Panella L, Lopresti M, Sforza C. Lower limbs kinematic assesssment of the efect of a gym and hydroterapy rehabilitation protocol after knee megaprosthesis: a case report, J Phys Ther Sci. 
2016;28:1064-1070.

17. Kim E, Kim T, Kang H, Lee J, Childers M.Aquatic versus land-based exercises as early functional rehabilitation for elite athletes with acute lower extremity ligament injury: a pilot study, PM\&R. 2010;2(8):703-712. [doi:

10.1016/j.pmrj.2010.03.012]

18. Jabbar K, Kudo S, Goh K, Goh M. Comparison in the three dimensional gait kinematics between young and older adults on land in shallow water, Gait Posture. 2017;57: 102-108. [doi.org/10.1016/j.gaitpost.2017.05.021] 19. Wondrasch B, Aron A, Rotterud JH, Hoysveen T, Bolstad K, Risberg MA. The feasibility of a 3-month active rehabilitation program for patients with knee full-thickness articular cartilage lesions: The Oslo cartilage active rehabilitation and education study, J Orthop Sport Phys. 2013;43(5): 310-324.

20. Yoo JD, Kim Nk. Distal femoral varization osteotomy, J Kor Orto Assoc. 2014;43:118-125.

21. Seo YR, Nha KW, Ha SS. Surgical technique for distal femur varization osteotomy, J Kor Ortho Assoc. 2018;53:301-306.

23. Yoshioka, T., Kubota, S., Sugaya, H., Hyodo, K., Ogawaz, K., Taniguchi, Y., Kanmori, A., Sankai, Y., \&Yamazaki, M. Robotic device-assisted knee extensio training during the early postoperative period after opening wedge high tibial osteotomy: a case report, J Med Case Rep. 2017;11: 213-222. DOI 10.1186/s13256-017-1367-3

24. Valtonen A, Poyhonent T, Sipila S, Heinonen A. Effects of Aquatic Resistance Training on Mobility Limitation and Lower-Limb Impairments After Knee Replacement, Arch Phys Med Rehabil. 2010;91(6):833-839.

[doi.org/10.1016/j.apmr.2010.03.002]

25. Bricca A, Roos E, Juhl C, et al. Infographic. Therapeutic exercise relieves pain and does not harm knee cartilage nor trigger inflammation, Br J Sports Med. 2019;[doi: 10.1136/bjsports-2019-100727]

\section{Appendix 1}

Aquatic Rehabilitation Program

Intervention Time: 10 weeks

\begin{tabular}{|c|c|c|}
\hline $\begin{array}{l}\text { Sessio } \\
\text { ns }\end{array}$ & Objective & Activities \\
\hline $\begin{array}{l}1 \text { st } \\
\text { week } \\
(3 \times 30 \\
\text { min) }\end{array}$ & $\begin{array}{l}\text { Knee } \\
\text { Mobilization and } \\
\text { Quadriceps } \\
\text { Stretching } \\
\text { Knee Extender } \\
\text { Stretch } \\
\text { Balance training }\end{array}$ & $\begin{array}{l}\text {-Walking in the pool - Knee } \\
\text { lift to } 90^{\circ} \text { Do the exercise } \\
\text { supported only on the right } \\
\text { knee, } \\
\text { bring the left leg forward / } \\
\text { backward / right / left, training } \\
\text { the balance. -Only load } \\
\text { (without moving left leg). } \\
\text { (with accessories) Time: } \\
\mathbf{3 0}\end{array}$ \\
\hline
\end{tabular}




\begin{tabular}{|c|c|c|}
\hline $\begin{array}{l}\text { 2nd } \\
\text { week } \\
(3 \times 60 \\
\text { min) }\end{array}$ & $\begin{array}{l}\text { Knee } \\
\text { Mobilization and } \\
\text { Quadriceps } \\
\text { Stretching } \\
\text { Knee Extender } \\
\text { Stretch } \\
\text { Balance training }\end{array}$ & $\begin{array}{l}\text {-Walking in the pool -Run in } \\
\text { the pool -Knee lift to } 90^{\circ} \text { with } \\
\text { drag and pull aid -Walk in the } \\
\text { pool and start running; lower } \\
\text { limb } \\
\text { elevation Do the exercise } \\
\text { supported by the right knee } \\
\text { only, } \\
\text { bring the left leg forward / } \\
\text { backward / right / left - At the } \\
\text { bottom of the pool kneeling } \\
\text { over your left } \\
\text { knee, bring your body } \\
\text { forward forcing your right } \\
\text { knee to bend to } 90^{\circ} \text { ( } 2 \text { X10 } \\
\text { repetitions) Time } \\
-60 \text { min }\end{array}$ \\
\hline $\begin{array}{l}\text { 3rd } \\
\text { to 6th } \\
\text { week } \\
(3 \times 60 \\
\text { min) }\end{array}$ & $\begin{array}{l}\text { Knee } \\
\text { mobilization and } \\
\text { quadriceps } \\
\text { stretching. } \\
\text { Knee Extender } \\
\text { Stretch } \\
\text { Balance training } \\
\text { Strengthen } \\
\text { Muscle Mass }\end{array}$ & $\begin{array}{l}\text { - Walking and Running in the } \\
\text { Pool - Do the exercise with } \\
\text { the straight knee support. Do } \\
\text { the exercise with the support } \\
\text { knee slightly bent, and lower } \\
\text { the support base } \\
\text { by placing the foot on heels / } \\
\text { toes. (Time: } 5 \text { minutes) - Up } \\
\text { and down the step, } \\
\text { sometimes going up with the } \\
\text { knee involved or now the } \\
\text { uninvolved ( } 2 \times 10 \text { reps) - } \\
\text { With your back to the step } \\
\text { and with the } \\
\text { affected leg above it, climb } \\
\text { the unaffected one. (4x10 } \\
\text { reps) - run more intensely } \\
\text { (use the shin guards) At the } \\
\text { bottom of the pool kneeling } \\
\text { over your left } \\
\text { knee, bring your body } \\
\text { forward by forcing your right } \\
\text { knee to bend - over } 90^{\circ} \text { (2 } \\
\text { x10 repetitions) Time: } \\
60 \text { min }\end{array}$ \\
\hline $\begin{array}{l}\text { 7th } \\
\text { and } \\
8 \text { th } \\
\text { week } \\
(3 \times 60 \\
\text { min) }\end{array}$ & $\begin{array}{l}\text { Knee } \\
\text { mobilization and } \\
\text { quadriceps } \\
\text { stretching. } \\
\text { Knee Extender } \\
\text { Stretch } \\
\text { Balance training } \\
\text { Strengthen } \\
\text { Muscle Mass }\end{array}$ & $\begin{array}{l}\text { - Walking and Running in the } \\
\text { Pool - Do the exercise with } \\
\text { the straight knee support. Do } \\
\text { the exercise with the support } \\
\text { knee slightly bent, and lower } \\
\text { the support base } \\
\text { by placing the foot on heels / } \\
\text { toes. (Time: } 5 \text { minutes) - Up } \\
\text { and down the step, } \\
\text { sometimes going up with the } \\
\text { knee involved or now the } \\
\text { uninvolved (2x10 reps) - } \\
\text { With your back to the step } \\
\text { and with the } \\
\text { affected leg above it, climb } \\
\text { the unaffected one. (4x10 } \\
\text { reps) - run more intensely } \\
\text { (use the shin guards) Time: } \\
\mathbf{4 5} \text { min Flapping legs, } \\
\text { flexing knees Supported } \\
\text { Swimming Time: } \\
\mathbf{1 5 m i n}\end{array}$ \\
\hline
\end{tabular}




\begin{tabular}{|c|c|c|}
\hline $\begin{array}{l}\text { 9th } \\
\text { and } \\
10 \text { th } \\
\text { weeks } \\
\text { (3x60 } \\
\text { min) }\end{array}$ & $\begin{array}{l}\text { Knee } \\
\text { Mobilization and } \\
\text { Quadriceps } \\
\text { Stretching. } \\
\text { Knee Extender } \\
\text { Stretch } \\
\text { Balance training } \\
\text { Strengthen } \\
\text { Muscle Mass }\end{array}$ & $\begin{array}{l}\text { - Walking and Running in the } \\
\text { Pool - Do the exercise with } \\
\text { the straight knee support. Do } \\
\text { the exercise with the support } \\
\text { knee slightly bent, and lower } \\
\text { the support base } \\
\text { by placing the foot on heels / } \\
\text { toes. (2x10 reps) - Up and } \\
\text { down the step, sometimes } \\
\text { going up with the } \\
\text { knee involved or now the } \\
\text { uninvolved (2x10 reps) - } \\
\text { With your back to the step } \\
\text { and with the } \\
\text { affected leg above it, climb } \\
\text { the unaffected one. (4x10 } \\
\text { reps) Time: } \\
\text { 20min Supported } \\
\text { swimming with and without } \\
\text { fins Leg beat varying } \\
\text { positions Time: } \\
\mathbf{4 0 ~ m i n ~}\end{array}$ \\
\hline
\end{tabular}

\section{Appendix 2}

\section{Declaration of Consent}

Case Study of a Varization Osteomomy

I, the undersigned (full name of the user),

have understood the explanation given to me about my clinical case and the intended research and the study in which I will be included. I was given the opportunity to ask the questions I deemed necessary, and all of them were answered satisfactorily. I understand that, in accordance with the recommendations of the Declaration of Helsinki, the information or explanation given to me concerned the objectives, the methods, the expected benefits, the potential risks and the possible discomfort. In addition, I have been informed that I have the right to refuse to participate in the study at all times, without prejudice to any assistance to me. Therefore, I consent to the method, treatment or inquiry proposed by the researcher.

Date:

Volunteer Signature:

The investigator in charge: Signature: 
